\title{
Uma proposta de taxonomia para a categorização das falhas no ambiente das cadeias de suprimentos
}

\author{
Mauricio Plaza-Carvajal \\ Mestrando; Universidade Federal de Santa Catarina, Florianópolis, SC, Brasil; \\ contato.plaza@gmail.com \\ Moisés Dutra \\ Doutor; Universidade Federal de Santa Catarina, Florianópolis, SC, Brasil; \\ moises.dutra@ufsc.br \\ Douglas Macedo \\ Doutor; Universidade Federal de Santa Catarina, Florianópolis, SC, Brasil; \\ douglas.macedo@gmail.com
}

\begin{abstract}
Resumo: A questão informacional permeia as mais diversas áreas do conhecimento. Em relação ao ambiente industrial, elevados custos são imputados à indústria em virtude de deficiências no ciclo informacional e no de mercadorias. Falhas ocasionam interrupções e rupturas nesses ciclos, reduzindo a competitividade das organizações. O trabalho debruça-se sobre a possibilidade de categorizar essas falhas na cadeia de suprimentos. O objetivo principal é, a partir de um olhar da Ciência da Informação (CI), propor uma taxonomia para as falhas existentes, tendo por base os seguintes objetivos: (i) identificar as principais falhas nas cadeias de suprimentos evidenciadas na literatura; (ii) posicionar cada falha dentro do fluxo logístico e informacional, e (iii) agrupar, organizar e hierarquizar essas falhas. Trata-se uma pesquisa bibliográfica, exploratória e qualitativa. Os resultados obtidos permitem afirmar que existem diversas similaridades nos termos que definem os locais e a origem das ocorrências de falhas, assim como, a percepção de que, com base na taxonomia proposta, há elevados riscos de interrupções e rupturas na cadeia de suprimentos. Finalmente, com o trabalho, espera-se contribuir com a ampliação da compreensão das falhas que acometem diversas organizações e, igualmente, com a geração de conhecimento para discussões futuras que envolvam as cadeias de suprimentos e a Ciência da Informação. Há um vasto espaço de colaboração no que tange à questão informacional na cadeia de suprimentos, que ainda não está devidamente preenchido pela CI. Neste sentido, este trabalho pretende, também, contribuir para diminuir um pouco tal lacuna.
\end{abstract}

Palavras-chave: Cadeia de suprimentos. Fluxos de informação. Falhas. Taxonomia. 


\section{Introdução}

$\mathrm{O}$ atual cenário tecnológico torna o panorama informacional cada vez mais decisivo nas mais diversas áreas do conhecimento. Nas cadeias de suprimentos, por exemplo, as cada vez mais curtas distâncias entre produtores e consumidores geram uma necessidade de maior agilidade nos ciclos de produção e na disponibilização de produtos e informações em escala global. Além disso, a internet e o uso massivo de dispositivos móveis tornaram esse consumidor cada vez mais exigente quanto à urgência no uso da informação para a tomada de decisões em tempo real. Para Rojas Mesa (2006), existe uma excessiva centralização das informações entre os geradores da informação, em detrimento do usuário que nem sempre as tem disponíveis no momento desejado.

Entende-se que o pleno acesso às informações seja um ponto-chave para o sucesso das organizações, e uma ruptura neste processo implica em perdas e prejuízos a todos os envolvidos. López Yepes (1998) afirma que o sucesso de uma rede de informações não reside na elevada quantidade de informações disponíveis, mas nos mecanismos que facilitam o acesso a esta informação por parte do usuário. Moreiro González (2002) complementa ao afirmar que o grande desafio não se encontra apenas no poder da tecnologia e do processamento de dados, mas também na capacidade em se desenvolver e disseminar informação como fonte igualmente geradora de vantagem competitiva.

Desta forma, no que tange à busca por novas ferramentas gerenciais, as cadeias de suprimentos surgem como um agrupamento de organizações em prol de objetivos comums, quanto à fidelização de clientes, reduzação de custos e elevado nível de atendimento pautado na disponibilidade da informação correta em tempo real.

Para Vital, Floriani e Varvakis (2010), uma das funções essenciais dos fluxos informacionais é dotar os gestores de subsídios imprescindíveis ao processo de tomada de decisões, tornando-se o gerenciamento da informação um instrumento estratégico para controlar e auxiliar decisões, por meio de melhorias no fluxo da informação, do controle, análise e consolidação da informação para os usuários. Contudo, e apesar das diversas ferramentas tecnológicas disponíveis 
no mercado, é perceptível que elas não têm sido suficientes para minimizar os problemas resultantes de falhas no fluxo da informação nas cadeias de suprimentos. O fluxo de informação deve ser contínuo e ininterrupto. Para Morigi, Semensatto e Binotto (2006), o ciclo informacional é dinâmico, não tem início nem fim, está sempre se autoalimentado, continuamente, por meio dos processos interativos e intercâmbios comunicativos que envolvem as necessidades de produção, transmissão e uso da informação.

Diante do exposto, e no intuito de verificar a existência de falhas no fluxo informacional, a pesquisa detectou mais de 100 ocorrências de falhas nas cadeias de suprimentos que geram interrupções permanentes ou temporárias no fluxo de informações e, também, no fluxo de movimentação física, evidenciando um elevado grau de integração e de coexistência entre estes dois fluxos.

A revisão detectou ainda que diversas falhas encontram-se repetidas ou apresentam sinônimos na literatura, o que justifica a necessidade de um prévio ordenamento e uma diminuição de redundâncias, juntamente com uma classificação e uma hierarquização dessas falhas. E, assim, surge o foco deste trabalho quanto à elaboração de uma taxonomia para a cadeia de suprimentos que possibilite a unificação de vocábulos e viabilize o acesso às informações pelos diversos usuários que compõem a cadeia de suprimentos. O questionamento que norteia esta pesquisa pode ser assim enunciado: é possível categorizar as falhas existentes na cadeia de suprimentos, no intuito de minimizar os custos que incidem neste ambiente?

Para elucidar tal pergunta-problema, o objetivo geral do trabalho é propor uma taxonomia para as falhas existentes nas cadeias de suprimentos, tendo como desdobramentos os seguintes objetivos: (i) identificar as principais falhas nas cadeias de suprimentos evidenciadas na literatura; (ii) posicionar cada falha dentro do fluxo logístico e (iii) agrupar, organizar e hierarquizar estas falhas. A pesquisa pode ser enquadrada como bibliográfica, exploratória e qualitativa, esperando-se ao final, que se possa estabelecer uma correta identificação das barreiras que ocasionam as falhas no fluxo de informações e de materiais. Como resultado, o trabalho propõe a elaboração de uma taxonomia para a cadeia de suprimentos que englobe as principais falhas nela existentes. 
Este artigo apresenta parte das contribuições originais de um projeto de dissertação de mestrado, que foi defendido e aprovado no Programa de PósGraduação em Ciência da Informação da Universidade Federal de Santa Catarina (PGCIN/UFSC). Desta forma, é importante ressaltar que não é objeto desse trabalho procurar redefinir ou apresentar novidades quanto à construção de taxonomias, mas, tão somente, aplicar essa ferramenta de organização do conhecimento em uma área, até aqui, tão pouco explorada pela Ciência da Informação.

Para um melhor entendimento, o artigo foi assim distribuído: a seção 1 contempla a introdução. A seção 2 aborda os aspectos conceituais da cadeia de suprimentos, seus fluxos e suas falhas. A seção 3 apresenta o conceito de taxonomia e a necessidade de uma construção para a cadeia de suprimentos e a proposta taxonômica para este ambiente. Por fim, a seção 4 traz a conclusão da pesquisa.

\section{A cadeia de suprimentos: conceito, fluxos e falhas}

Esta seção aborda os principais conceitos sobre a cadeia de suprimentos e os relacionamentos existentes entre os seus componentes. Para Bowersox e Closs (2001), a cadeia de suprimentos é uma estratégia empresarial que envolve todos os elementos de uma cadeia de produção, na qual a cooperação entre os membros da cadeia reduzirá os riscos individuais e poderá, potencialmente, melhorar a eficiência do processo logístico, eliminando perdas e esforços desnecessários. Chopra e Meindl (2003) afirmam que a cadeia de suprimentos não inclui apenas fabricantes e fornecedores, mas também transportadores, depósitos, varejistas e os próprios clientes.

Neste contexto, a cadeia de suprimentos pode ser percebida como sendo um somatório de quatro macroprocessos: suprimentos, produção, distribuição e consumo. Christopher (2009) incrementa o conceito de cadeia de suprimentos, ao afirmar que a mesma compreende uma rede de organizações conectadas e interdependentes, trabalhando conjuntamente, em regime de cooperação mútua, para controlar, gerenciar e aperfeiçoar o fluxo de informações e de matériasprimas dos fornecedores para os clientes finais. 
Assim, a informação deve transitar por toda a cadeia de suprimentos, tendo como foco a informação de qualidade, confiável e útil a todos os envolvidos. O processo logístico inicia com as necessidades de consumo. Entretanto, e no que tange ao aspecto operacional, o macroprocesso de suprimentos inicia o ciclo ao prever a demanda e efetuar o processo de seleção de fornecedores. O macroprocesso de produção engloba as atividades de planejamento e controle da produção, movimentando as matérias-primas em todo o ciclo produtivo. O macroprocesso de distribuição, por sua vez, é responsável pela transferência de produto acabado aos centros de distribuição, objetivando garantir a entrega de produto ao consumidor final dentro dos prazos exigidos. O macroprocesso de consumo, por fim, envolve as necessidades de consumo, assim como a compra e o uso dos produtos que são movimentados ao longo da cadeia de suprimentos.

A Figura 1 evidencia os quatro macroprocessos da cadeia de suprimentos e os fluxos de movimentação de informações e de movimentação física de mercadorias. Esses fluxos coexistem simultaneamente, iniciando pelas informações quanto às necessidades de consumo e ao fluxo de mercadorias que produz e direciona os produtos aos consumidores.

Figura 1 - A Cadeia de Suprimentos, fluxos e a origem das falhas

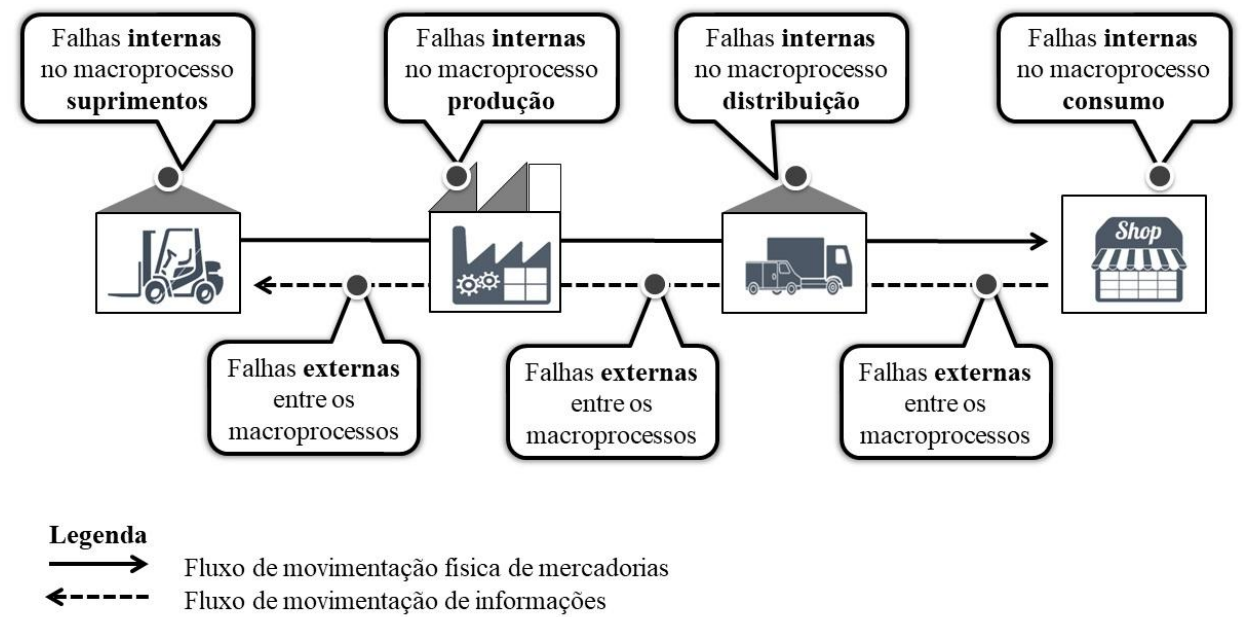

Fonte: Elaborado pelos autores. 
No que tange à interligação dos quatro macroprocessos, Scheidegger et al. (2015) afirmam que o fluxo de materiais em uma cadeia de suprimentos - dos fornecedores em direção aos consumidores - é coordenado por um fluxo de informações em sentido contrário. Sobre esta temática, Bowersox e Closs (2001) afirmam que informações precisas e em tempo hábil são cruciais para a eficácia na cadeia de suprimentos, por três razões básicas: (i) os clientes consideram informações sobre status de pedido, disponibilidade de produto, programação de entrega e faturamento como fatores essenciais no serviço ao cliente; (ii) o objetivo central de redução de estoques, em toda a cadeia de suprimento, tem levado os executivos a considerar que a informação pode ser um instrumento eficaz na redução de estoque e da necessidade de recursos humanos; e (iii) a informação aumenta a flexibilidade para decidir como, quando e onde os recursos podem ser utilizados para que se obtenha vantagem estratégica.

Falhas geram impacto negativo em toda a cadeia de suprimentos e diminuem a competitividade em âmbito nacional e internacional. Para Hilsdorf et al. (2005), cada membro da cadeia de suprimentos pode estar envolvido em vários processos (de negócios) que ultrapassam suas fronteiras e que estão sujeitos a desvios e interrupções pela ocorrência de falhas de comunicação ou coordenação. Os autores complementam essa afirmação, quando citam que as falhas podem ocorrer no fluxo de informações, na direção dos consumidores até os fornecedores, e no fluxo de materiais, na direção dos fornecedores até os consumidores. O local de origem dessas falhas encontra-se evidenciado, igualmente, na Figura 1.

A revisão da literatura tornou possível separar a origem das falhas em interna e externa. As falhas internas aos macroprocessos acontecem individualmente e dentro das fronteiras de cada organização. Assim, no macroprocesso de suprimentos, existem falhas entre os fornecedores quanto a atrasos, processos pouco flexíveis nas entregas e materiais fora dos padrões solicitados. No macroprocesso de produção, existem falhas estratégicas quanto ao momento exato de iniciar o processo produtivo, assim como falhas quanto ao processo logístico interno de controle de estoques, armazenagem e 
movimentação de materiais. No macroprocesso de distribuição, foram detectadas falhas no trato com o produto resultante de avarias e não conformidades e nos processos específicos de distribuição. Tais falhas internas finalizam no macroprocesso de consumo quanto à solicitação de pedidos pelos clientes sem programação ou com poucas especificações, incertezas quanto às necessidades de consumo ou produtos não consumidos por falhas de embalagens ou avarias. A lista completa com as falhas nos quatro macroprocessos está evidenciada no quadro a seguir:

Quadro 1 - Falhas internas nos macroprocessos - detalhadas

\section{Suprimentos [Origem no fornecedor] - Autor / Ano / Falha}

Carvalho, Gatts e De Azevedo Júnior (1998) - Problemas com qualidade e pontualidade e falta de parceria. Soares (2007) - Não entrega; envios errados por erros em notas fiscais; mal uso de informações sobre demanda. Vakharia et al. (2009) - Reduzida capacidade de abastecimento; falta de confiabilidade. Sodhi et al. (2012) - Interrupção de fornecedores internacionais. Sellitto et al. (2012) - Alta dependência, criticidade, flexibilidade. Revista... (2013) - Reduzido acesso a fornecedores no exterior. Snyder et al. (2016) - Reduzida capacidade de abastecimento; elevado número de fornecedores. Aguiar et al. (2015) - Reduzida capacidade de abastecimento; falhas na redução de custos; não cumprimento dos prazos; inadimplência/falência; riscos de localização geográfica; falta de confiabilidade. Albani et al. (2016) - Falhas na seleção. Hudnurkar et al. (2016) - Custo ou Criticidade do item [elevado]; compartilhamento do risco [falta]; grau de inovação [baixo]; cumpre prazos de entrega [falha]; competência técnica [baixa]; histórico de fornecimento [negativo]; grau de dependência [elevado]; transferência de conhecimento [falha]; poder de decisão [elevado].

\section{Suprimentos [Origem na Matéria-prima] - Autor / Ano / Falha}

Aravechia e Pires (2000) - Atraso de entrega. Soares (2007) - Problemas de qualidade; diferenças de inventário na fábrica. Vakharia et al. (2009) - Falta por interrupção. Schmidt e Raman (2012) - Ruptura. Revista... (2013) - Elevada burocracia na importação; multas nos processos de importação; elevado custos de armazém na importação. Aguiar et al. (2015)Ausência de estoque-pulmão; falta por interrupção. Teixeira et al. (2016) - Excesso de peças em processo. Albani et al. (2016) - Erros de planejamento.

\section{Suprimentos [Origem no Processo] - Autor / Ano / Falha}

Vakharia et al. (2009) - Falta de informação sobre ressuprimento. Aguiar et al. (2015) - Falhas no fluxo de materiais; falta de recursos no poder de negociação. Albani et al. (2016) - Rota e velocidade mal dimensionadas; mudanças constantes nas exigências. 


\section{Produção [Origem nas Estratégias de Produção] - Autor / Ano / Falha}

Soares (2007) - Falta de acompanhamento do comprador; problemas ao dimensionar o espaço físico. Albani et al. (2016) - Erro na escolha do processo de manufatura.

\section{Produção [Origem no Processo] - Autor / Ano / Falha}

Aravechia e Pires (2000) - Baixo Lead time da manufatura. Soares (2007) - Produção em excesso. Vakharia et al. (2009) - Falhas de fabricação. Brüning et al. (2015) - Just in Time não permite margens de atrasos. Teixeira et al. (2016) - Produzir excessivamente; produzir cedo demais. Aguiar et al.(2015) - Falta de qualidade do sistema produtivo. Albani et al. (2016) Lead-Time maior que o esperado.

\section{Distribuição [Origem no Produto] - Autor / Ano / Falha}

Soares (2007) - Erros na solicitação de informações sobre produtos. Branski (2008) - Falta de produtos. Revista... (2014) - Necessidade de redução de custos na exportação.

\section{Distribuição [Origem no Processo] - Autor / Ano / Falha}

Soares (2007) - Falha atualização estoque/reposição junto ao varejo. Valor... (2012) Dificuldade para entregas urbanas. Revista... (2013) - Desconhecimento de processos de exportação.

\section{Consumo [Quanto ao Consumidor] - Autor / Ano / Falha}

Aravechia e Pires (2000) - Baixo tempo de resposta; atraso de seus pedidos. Vakharia et al. (2009) - Pedidos não atendidos. Aguiar et al. (2015) - Pedidos não previstos. Albani et al. (2016) - Nível de serviço não atendido. 


\section{Consumo [Quanto à Demanda] - Autor / Ano / Falha}

Soares (2007) - Variabilidade. Vakharia et al. (2009) - Incertezas; variabilidade. Valor... (2012) Vendas perdidas. Aguiar et al. (2015) - Falta de ajuste de previsões; falhas no ajuste no volume de produtos; informações insuficientes/distorcidas.

Consumo [Quanto ao oferta] - Autor / Ano / Falha

Vakharia et al. (2009) - Incertezas. Aguiar et al. (2015) - Produto sem aceitação.

Fonte: Elaborado pelos autores.

O Quadro 1 traz uma versão detalhada da Figura 1, no que tange às falhas internas na cadeia de suprimentos e o seu respectivo local de ocorrência dentro dos macroprocessos, sendo atrelado às ocorrências o respectivo autor.

Em relação às falhas que acontecem no ambiente externo aos macroprocessos, a literatura deixa claro que existem descontinuidades nos fluxos de informações e de movimentação físicas, resultantes, em grande parte, pela falta de uso de ferramentas de Tecnologia da Informação (TI), pelas deficiências na infraestrutura de transportes, pelo excesso de burocracia e de regulamentação por parte do governo, além de falhas no próprio processo de relacionamento interorganizacional, conforme evidenciado na Figura 2. Ela apresenta, de forma detalhada, as falhas no ambiente externo aos macroprocessos, não sendo mencionadas na pesquisa interrupções nos fluxos ocasionados por eventos da natureza, tais como chuvas, enchentes, terremotos, dentre outros. Parte-se do princípio de que as falhas detectadas na literatura são aquelas que, em tese, deveriam ser controladas pelos gestores da cadeia. Sendo assim, a Figura 2 aborda as principais falhas que acontecem entre os macroprocessos da cadeia de suprimentos, sendo atrelado a cada ocorrência o respectivo autor constante na literatura.

A análise das falhas internas e externas nos macroprocessos permite constatar que existem duplicidades e sinônimos entre os autores. A necessidade 
de reduzir as redundâncias vai ao encontro de Dutra et al. (2013), quando afirmam que representar formalmente um processo, produto ou serviço significa dar um passo fundamental no sentido de se eliminar a ambiguidade e de se melhorar a comunicação entre os diferentes grupos de trabalhos envolvidos na cadeia de suprimentos. Diante do exposto, julga-se como prévia condição para a solução das falhas na cadeia de suprimentos um enxugamento destas duplicidades, procurando agrupar as falhas em categorias que permitam estabelecer prioridades no diagnóstico de soluções e antecipação de problemas futuros. 


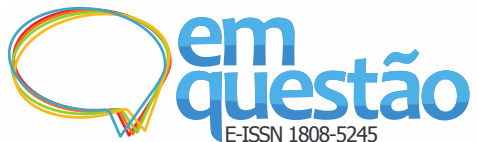

ma proposta de taxonomia para categorização das falhas no ambiente das cadeias de suprimentos Maurício Plaza-Carvajal, Moisés Dutra, Douglas Macedo

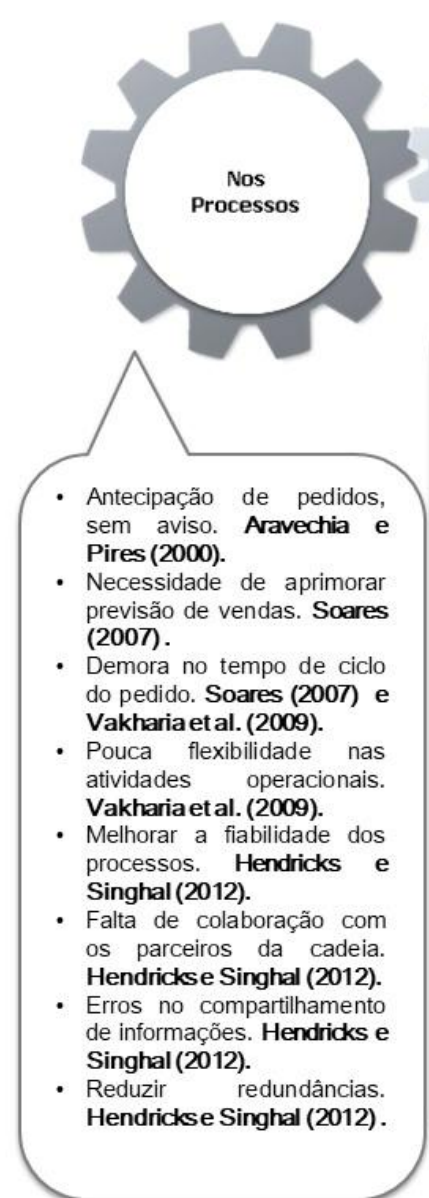

Figura 2 - Falhas externas aos macroprocessos - detalhadas

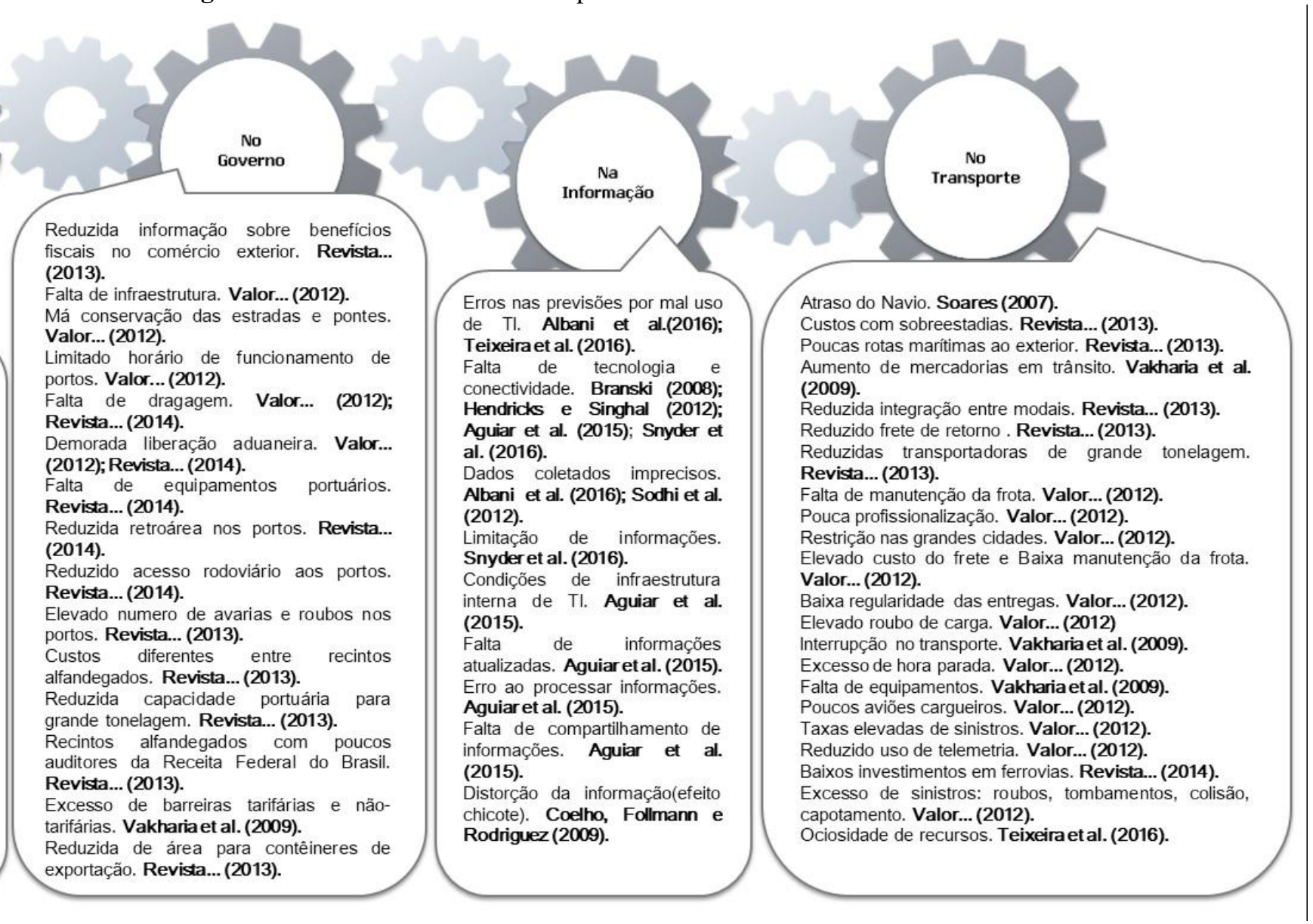

Fonte: Elaborado pelos autores. 


\section{A taxonomia e a cadeia de suprimentos}

A cadeia de suprimentos denota, por meio dos seus fluxos, um comportamento sistêmico, no qual a troca de informações com o seu ambiente e a conectividades dos seus componentes é condição necessária para a obtenção de vantagem competitiva e para a continuidade ininterrupta dos seus processos.

Para Dutra et al. (2013), a obtenção de resultados estratégicos na cadeia de suprimentos depende diretamente da integração sistêmica de processos físicos e virtuais, basicamente, da qualidade do gerenciamento de uma quantidade significativa de informações disponíveis para tomada de decisão, tanto quanto possível, de forma rápida, integrada, interligada, segura, cooperativa e em tempo real. Contudo, para Vital (2007), as organizações encontram dificuldade em prover acesso às informações, e essa dificuldade é muito maior quando se trata de informações que não apresentam estrutura, mas que podem ser importantes para outras pessoas dentro da organização e precisam ser compartilhadas, a exemplo de relatórios de desempenho operacional ou indicadores de desempenho logístico.

Figura 3 - Estrutura hierárquica da taxonomia
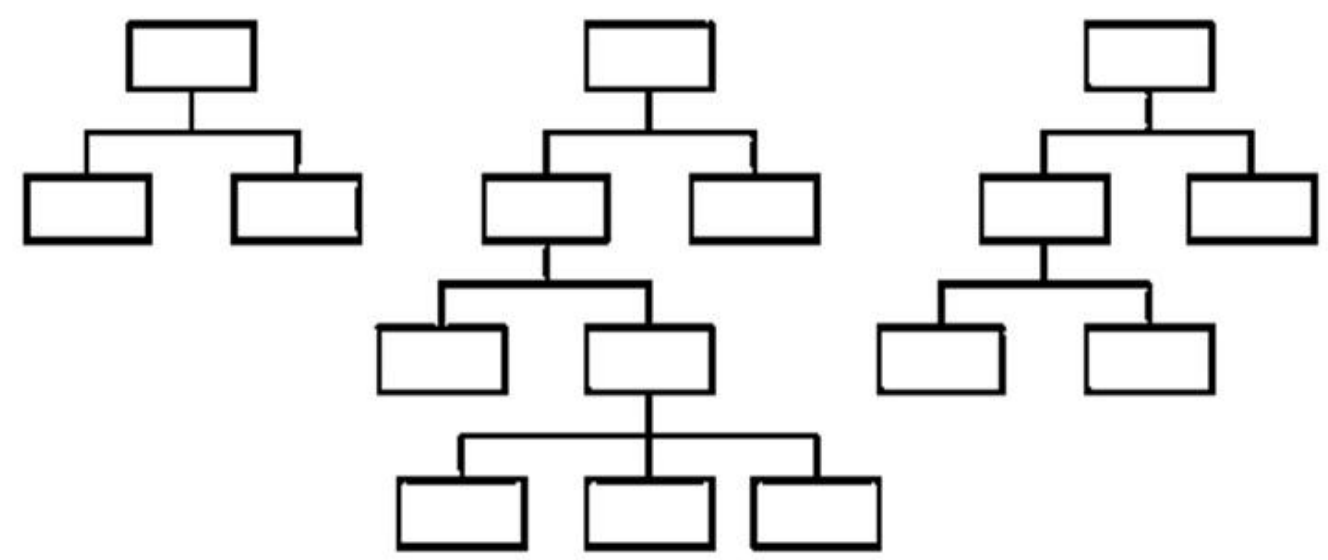

Fonte: Capar, Ulengin e Reisman (2004).

Diante dessa realidade, Yamaoka, Carvalho e Gauthier (2012) afirmam que, na busca por uma base conceitual que possibilitasse o agrupamento de palavras que caracterizassem os problemas na cadeia de suprimentos, surge a taxonomia como sendo uma forma de vocabulário controlado, que é uma lista de 
termos selecionados, de forma a eliminar ambiguidades, evitando o uso do mesmo termo com diferentes conceitos. De forma complementar, Martínez et al.(2004) afirmam que a taxonomia implica na criação de uma estrutura (ordem) e de nomes que propiciam localizar a informação considerada mais importante e relevante. Ou seja, é a implementação de um ordenamento e rotulação de metadados, sendo a estrutura hierárquica a forma mais comum de representação, conforme evidenciado na Figura 3.

Figura 4 - Tipos de taxonomia

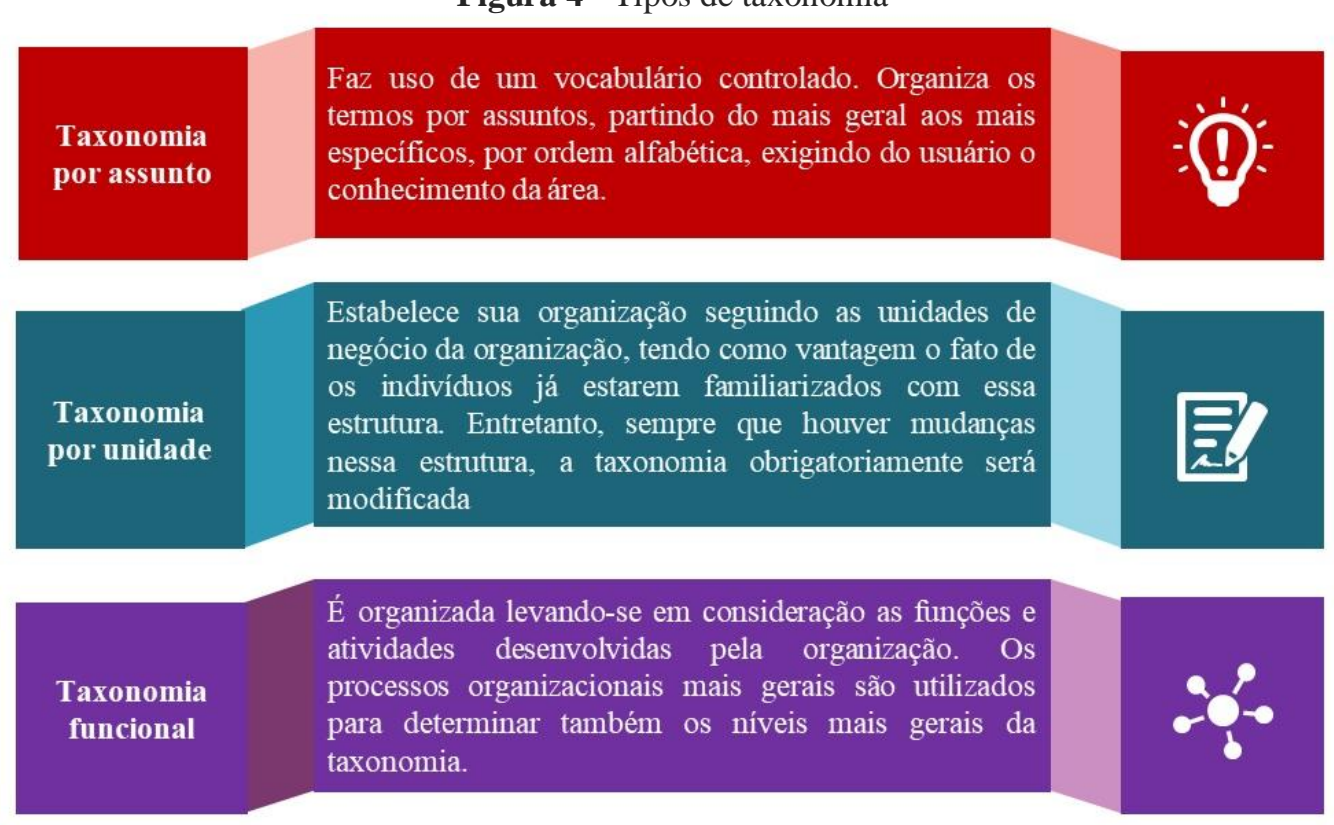

Fonte: Elaborado pelos autores a partir de Blackburn (2006).

Vital (2007) afirma que as taxonomias promovem o elo entre os indivíduos e a informação. Nessa linha, Figueiredo (2006) expande essa afirmação, quando cita que a necessidade de administrar as informações e o seu impacto na gestão estratégica das organizações fez com que as taxonomias pudessem ser destinadas para uso externo (fora da companhia) ou interno. Woods (2004) faz menção ao uso corporativo da taxonomia, quando reitera que a taxonomia é uma hierarquização de categorias utilizadas para classificar os documentos e outras informações, sendo uma forma de representar as informações disponíveis dentro de uma empresa.

Assim, e no intuito de ampliar as bases conceituais que vinculam a taxonomia com o ambiente corporativo, Blackburn (2006) afirma que, na visão 
hierarquizada da taxonomia, cada categoria subsequente é um subconjunto da categoria de nível mais elevado, existindo assim três tipos básicos de taxonomias hierárquicas: (1) assunto; (2) unidade de negócio e (3) funcional, conforme evidenciado na Figura 4. Assim, a seção seguinte tem como objetivo propor uma taxonomia para as falhas existentes na cadeia de suprimentos, efetuando uma classificação por palavras-chave e de uso nos quatro macroprocessos já mencionados.

\subsection{A necessidade de uma taxonomia para as falhas na cadeia de suprimentos}

O Quadro 1 e a Figura 2 tornam evidente a necessidade de uma taxonomia para a cadeia de suprimentos ao serem percebidas falhas com nomes similares: falta de pontualidade, atrasos na entrega, lead-time (tempo entre a chegada e a entrega do pedido) elevado, baixo tempo de resposta, transportadora com atraso e entregas fora do horário que são, essencialmente, problemas de tempo, assim como outras evidenciadas na literatura.

Entende-se que o relacionamento interorganizacional, na cadeia de suprimentos, retroalimenta-se por meio de um fluxo contínuo e ininterrupto que permite a integração e o compartilhamento das informações entre os envolvidos para proporcionar uma correta tomada de decisões aos gestores deste sistema. Nesse sentido, Chandra e Tumanyan (2003) afirmam que a cadeia de suprimentos lida com problemas que estão interligados uns aos outros, e o isolamento de qualquer um dos envolvidos pode comprometer a veracidade das informações que circulam entre os fluxos.

Assim, e no intuito de minimizar os efeitos das falhas nos quatro macroprocessos da cadeia de suprimentos, entende-se ser necessário utilizar uma ferramenta que permita identificar e organizar tais falhas, tendo em vista que, a depender do tipo problema, deverá ser escolhida a melhor solução possível. Nessa linha de pensamento, Chandra e Tumanyan (2003) afirmam que existe a necessidade de um modelo comum de informações, e sua estruturação (taxonomia) pode ser aplicada a cada um dos quatro macroprocessos. Isso acontece porque as ferramentas de tomada de decisão (sistemas) precisam de 
mecanismos para acesso a esses dados, recuperando as informações sobre um determinado problema e criando modelos para processar e trabalhar com as elas. Os autores afirmam ainda, que a taxonomia oferece a classificação desses problemas, seus relacionamentos e suas características. Chandra e Tumanyan (2004) afirmam, ainda, que as organizações que compõem a cadeia de suprimentos apresentam diferentes tipos de sistemas de informação em sua maioria incompatíveis entre si. Torna-se, assim, necessária uma abordagem unificada, no que tange ao vocabulário a ser utilizado e uma representação que proporcione uma plena integração.

\subsection{Etapas para elaboração de uma taxonomia}

A elaboração de uma taxonomia, em determinado campo do conhecimento, implica em uma visão sistêmica em relação à organização e à classificação dos seus componentes. Isso quer dizer que deve existir um mapeamento completo, sendo evidenciados os vínculos entre as diversas categorias que o compõem. Medeiros (2013) afirma que no desenvolvimento das taxonomias, e para que elas cumpram o papel de bem atender aos seus usuários, fatores importantes devem ser considerados, começando pelo seu dimensionamento e, consequentemente, fases de construção.

Contudo, para Vital (2012) o objetivo da taxonomia não é unicamente classificar e facilitar o acesso à informação. Terra et al. (1998) afirmam que o objetivo é, também, representar conceitos, agilizar a comunicação entre especialistas, encontrar consenso e oferecer um mapa da área. Para o autor, as organizações necessitam desenvolver categorias e estruturas de informação que façam sentido para seus próprios negócios e comunidades específicas de usuários. Campos e Gomes (2007) completam essa visão, ao afirmar que as taxonomias caracterizam-se por possibilitar a organização e a recuperação de informação e ser um instrumento de organização intelectual, atuando como um mapa conceitual dos tópicos explorados.

Assim, e no que tange à elaboração de uma taxonomia, Vital e Café (2011) afirmam que, inicialmente, deve existir uma coleta dos termos, sendo 
uma consulta à literatura especializada ou às classificações existentes na organização. Após a coleta dos termos, é necessário padronizá-los, para que todos os usuários 'falem a mesma língua'. $\mathrm{Na}$ etapa seguinte, levam-se em consideração as relações semânticas entre os termos, que podem ser de equivalência, hierárquicas e não hierárquicas, assim como polihierárquicas. As relações de equivalência estabelecem-se entre termos sinônimos. A análise dos termos sinônimos precisa corresponder às necessidades e preferências do grupo de usuários.

Vital e Café (2011) afirmam ainda que, nas relações de polihierarquia, um mesmo termo pode estar subordinado a mais de um termo genérico, sendo mais frequente este tipo de relação no ambiente organizacional. O termo 'matéria-prima' é um exemplo. Na área financeira, este termo é considerado como um item de custo; na área de produção é um tipo de insumo. O termo 'matéria-prima' aparecerá ligado a dois ou mais termos genéricos. O termo matéria-prima é considerado na área contábil como um ativo.

Para Vogel (2010), o desenvolvimento de uma taxonomia, de maneira geral, obedece a alguns passos. Primeiramente, é necessário compreender o fluxo informacional da organização ou da área de conhecimento em estudo, por meio de um diagnóstico. Posteriormente, torna-se necessário buscar exemplos das informações que circulam nesse ambiente, no intuito de coletar o máximo de informações que irão compor a taxonomia inicial.

Seguindo a sequência de passos, as informações coletadas devem ser analisadas no intuito de gerar uma estrutura inicial de taxonomia. A estrutura resultante deve ser submetida para análise e validação dos usuários das informações a fim de efetuar crítica e melhorias. Após essa validação, os resultados devem ser avaliados e revisados para consolidar a estrutura taxonômica e ser levada à validação estratégica da organização para uma classificação de uma amostra piloto, com posterior divulgação e publicação da estrutura taxonômica. Contudo, esse processo não finaliza aí. Tornam-se necessárias a manutenção e revisão periódica da taxonomia, para verificar a inclusão de novos termos, assim como novas necessidades de classificação, e não perder os benefícios gerados pela organização da informação. 


\subsection{Uma proposta de taxonomia para as falhas na cadeia de suprimentos}

Em relação à elaboração de uma proposta taxonômica que unifique e integre os vocábulos coletados e analisados em mais de 100 falhas evidenciadas na literatura, a Figura 1 inicia o processo ao agrupar as falhas conforme o local de origem em cada macroprocesso. Posteriormente, foi elaborado o Quadro 2 que agrupa as falhas internas em quatro palavras-chave, que alocam as falhas de acordo com o seu grau de risco, no que tange a variabilidade, a ausência, o aumento ou a redução de alguma ação dentro dos macroprocessos.

Quadro 2 - Classificação das falhas internas na cadeia de suprimentos, por macroprocesso. Classificação das falhas no macroprocesso - SUPRIMENTOS - Tipo de Falha / Origem / Descrição [impacto]

\begin{tabular}{|c|c|c|}
\hline \multirow{4}{*}{ 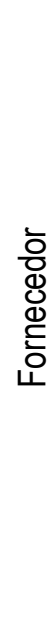 } & Aumento & $\begin{array}{l}\mathrm{N}^{0} \text { fornecedores - Distância geográfica fornecedor - Dependência do } \\
\text { fornecedor - Criticidade do material - Histórico negativo - Dependência } \\
\text { junto ao fornecedor - Poder de decisão do fornecedor. [Falha } \\
\text { temporária/interrupção em ambos os fluxos]. }\end{array}$ \\
\hline & Ausência & $\begin{array}{l}\text { Abastecimento - Seleção de fornecedores - Confiabilidade - Fornecedor } \\
\text { [falência] - Qualidade - Parceria do fornecedor. [Falha definitiva/ruptura } \\
\text { no fluxo físico]. }\end{array}$ \\
\hline & Redução & $\begin{array}{l}\text { Acesso a fornecedores - Margens para reduzir custos - } \\
\text { Compartilhamento de risco - Grau de inovação - Competência técnica - } \\
\text { Transferência de conhecimento. [Falha temporária/interrupção em } \\
\text { ambos os fluxos]. }\end{array}$ \\
\hline & Variabi & $\begin{array}{l}\text { Entrega - Cumprimento de prazos - Envio de notas fiscais - Uso de } \\
\text { informações - Fornecedor internacional }- \text { Pontualidade. [Falha } \\
\text { temporária/interrupção em ambos os fluxos] }\end{array}$ \\
\hline \multirow{4}{*}{ 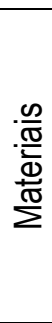 } & Aume & $\begin{array}{l}\text { Custos de armazenagem na importação - Burocracia na importação - } \\
\text { Multas na importação de matéria-prima - } n^{0} \text { de peças em processo. } \\
\text { [Falha temporária/interrupção no fluxo físico] }\end{array}$ \\
\hline & Ausência & $\begin{array}{l}\text { Estoque Pulmão - Qualidade dos materiais - Materiais (ruptura). [Falha } \\
\text { definitiva/ruptura no fluxo físico] }\end{array}$ \\
\hline & & Planejamento de materiais. [Falha temporária/interrupção no fluxo físico] \\
\hline & Varial & Entrega - Inventário. [Falha temporária/interrupção no fluxo físico] \\
\hline \multirow{4}{*}{ 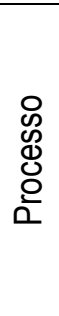 } & Aun & 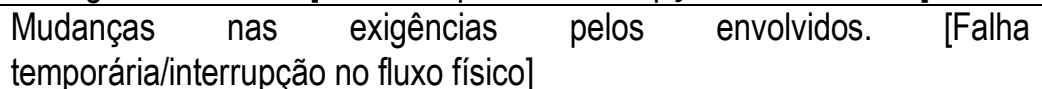 \\
\hline & Ausê & $\begin{array}{l}\text { Informações sobre ressuprimento. [Falha definitiva/ruptura no fluxo } \\
\text { físico] }\end{array}$ \\
\hline & Redu & Poder de negociação do fornecedor. [Falha interrupção no fluxo físico] \\
\hline & Varial & $\begin{array}{l}\text { Ciclo de materiais - roteirização. [Falha temporária/interrupção no fluxo } \\
\text { físico] }\end{array}$ \\
\hline \multicolumn{3}{|c|}{$\begin{array}{c}\text { Classificação das falhas no macroprocesso - PRODUÇÃO - Tipo de Falha / Origem / } \\
\text { Descrição [impacto] }\end{array}$} \\
\hline \multirow{2}{*}{ 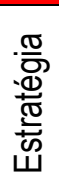 } & Ausência & $\begin{array}{l}\text { Acompanhamento do comprador. [Falha temporária/interrupção no fluxo } \\
\text { de informações] }\end{array}$ \\
\hline & Variab & $\begin{array}{l}\text { Dimensionamento do espaço físico - Erro na escolha do processo de } \\
\text { manufatura. [Falha temporária/interrupcão no fluxo físicol }\end{array}$ \\
\hline
\end{tabular}




\begin{tabular}{|c|c|c|}
\hline \multirow{4}{*}{ 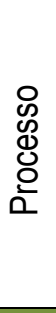 } & Aumento & $\begin{array}{l}\text { Lead-Time - Excessivo de Produção. [Falha temporária/interrupção no } \\
\text { fluxo físico]. }\end{array}$ \\
\hline & Ausência & $\begin{array}{l}\text { Qualidade do sistema produtivo. [Falha temporária/interrupção no fluxo } \\
\text { físico] }\end{array}$ \\
\hline & Reduc & Lead time da manufatura. [Falha temporária/interrupção no fluxo físico]. \\
\hline & Variak & $\begin{array}{l}\text { Na fabricação - Just in Time - Produção. [Falha temporária/interrupção } \\
\text { no fluxo físico]. }\end{array}$ \\
\hline \multicolumn{3}{|c|}{$\begin{array}{c}\text { Classificação das falhas no macroprocesso - DISTRIBUIÇÃO - Tipo de Falha / Origem / } \\
\text { Descrição [impacto] }\end{array}$} \\
\hline \multirow{2}{*}{$\begin{array}{l}\frac{0}{3} \\
\text { 은 } \\
\text { 인 }\end{array}$} & Ause & $\begin{array}{l}\text { Informações sobre produto - Produtos. [Falha definitiva/ruptura em } \\
\text { ambos os fluxos]. }\end{array}$ \\
\hline & Redu & $\begin{array}{l}\text { Necessidade de redução de custos na exportação. [Falha } \\
\text { temporária/interrupção no fluxo físico]. }\end{array}$ \\
\hline \multirow{2}{*}{$\begin{array}{l}\text { O } \\
\mathscr{W} \\
\text { ర్ } \\
\text { வ }\end{array}$} & Ausê & $\begin{array}{l}\text { Conhecimento de processos de exportação. } \\
\text { temporária/interrupção no fluxo de informações]. }\end{array}$ \\
\hline & Variabi & $\begin{array}{l}\text { de reposição junto ao varejo } \\
\text { a/ruptura no fluxo físico]. }\end{array}$ \\
\hline
\end{tabular}

Classificação das falhas no macroprocesso - CONSUMO- Tipo de Falha / Origem / Descrição [impacto]

\begin{tabular}{|c|c|c|}
\hline \multirow{3}{*}{ 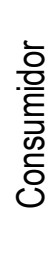 } & Ausência & Atendimento aos Pedidos. [Falha definitiva/ruptura no fluxo físico]. \\
\hline & Redução & $\begin{array}{l}\text { Reduzido tempo de resposta - Nível de serviço. [Falha } \\
\text { temporária/interrupção no fluxo físico]. }\end{array}$ \\
\hline & Variabilidade & $\begin{array}{l}\text { Entrega dos pedidos - Pedidos não previstos. } \\
\text { temporária/interrupção no fluxo físico]. }\end{array}$ \\
\hline \multirow{2}{*}{ 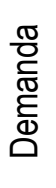 } & Ausência & Produtos a serem vendidos. [Falha definitiva/ruptura no fluxo físico]. \\
\hline & Variabilidade & $\begin{array}{l}\text { Ajuste de previsões - Demanda (efeito chicote) - Volume de produtos - } \\
\text { Informações (insuficiência ou distorção). [Falha temporária/interrupção } \\
\text { em ambos fluxos] }\end{array}$ \\
\hline \multirow{2}{*}{$\begin{array}{l}\frac{\pi}{5} \\
\frac{\omega}{0}\end{array}$} & Redução & $\begin{array}{l}\text { Reduzida aceitação de produtos. [Falha temporária/interrupção no fluxo } \\
\text { físico]. }\end{array}$ \\
\hline & Variabilidade & $\begin{array}{l}\text { Incertezas na oferta de produtos. [Falha temporária/interrupção no fluxo } \\
\text { físico]. }\end{array}$ \\
\hline
\end{tabular}

Fonte: Elaborado pelos autores.

Vale ressaltar que o objetivo da pesquisa não se esgota nas falhas mencionadas, até porque, novos cenários, novas tecnologias e novas exigências de consumo trazem consigo novas falhas. Contudo, trata-se de organizar, com algum grau de coerência e com uso da taxonomia, as falhas que foram evidenciadas. O Quadro 2 evidencia, também, o local de impacto de cada uma das falhas, podendo ser no fluxo de informações, fluxo de movimentação de mercadorias ou em ambos simultaneamente. Igualmente, são evidenciadas a origem de cada falha e em qual macroprocesso ela foi verificada. A última coluna implica em um elevado grau de criticidade, por dividir as falhas em dois 
tipos: definitiva ou temporária, sendo que a primeira ocasiona uma ruptura na cadeia de suprimentos e a segunda ocasiona uma interrupção.

O Quadro 3 traz a classificação das falhas externas na cadeia de suprimentos, por local de origem. Esse quadro envolve, basicamente, questões operacionais, tendo vista tratar-se das falhas que acontecem entre os macroprocessos da cadeia de suprimentos. Assim, são evidenciadas, por exemplo, falhas com reduzida abordagem na literatura, a exemplo de deficiências de infraestrutura em portos, aeroportos e estradas e burocracia em pontos de entrada e saída de mercadorias com destino ou originárias do exterior.

Quadro 3 - Classificação das falhas externas na cadeia de suprimentos, por local de origem.

\begin{tabular}{|c|c|c|c|}
\hline \multicolumn{4}{|c|}{ ORIGEM: GOVERNO } \\
\hline Falha & Descrição & Impacto & Tipo de Falha \\
\hline Ausência & $\begin{array}{l}\text { Má conservação das estradas e pontes - Falta de } \\
\text { dragagem }\end{array}$ & Fluxo Físico & $\begin{array}{l}\text { Definitiva } \\
\text { [Ruptura] }\end{array}$ \\
\hline Variabilidade & $\begin{array}{l}\text { Demorada liberação aduaneira - Custos } \\
\text { diferentes entre recintos alfandegados }\end{array}$ & $\begin{array}{l}\text { Fluxo Físico } \\
\text { e Inform. }\end{array}$ & $\begin{array}{c}\text { Temporária } \\
\text { [Interrupção] }\end{array}$ \\
\hline Aumento & $\begin{array}{l}\text { Elevado número de avarias e roubos nos portos - } \\
\text { Excesso de barreiras tarifárias e não-tarifárias }\end{array}$ & $\begin{array}{l}\text { Fluxo Físico } \\
\text { e Inform. }\end{array}$ & $\begin{array}{c}\text { Temporária } \\
\text { [Interrupção] }\end{array}$ \\
\hline Redução & $\begin{array}{l}\text { Reduzida informação sobre benefícios fiscais no } \\
\text { comércio exterior - Falta de infraestrutura - } \\
\text { Limitado horário de funcionamento de portos - } \\
\text { Falta de equipamentos portuários - Reduzida } \\
\text { retroárea nos portos - Reduzido acesso } \\
\text { rodoviário aos portos - Reduzida capacidade } \\
\text { portuária para grande tonelagem - Recintos } \\
\text { alfandegados com poucos auditores da RFB - } \\
\text { Reduzida de área para contêineres de } \\
\text { exportação }\end{array}$ & $\begin{array}{l}\text { Fluxo Físico } \\
\text { e Inform. }\end{array}$ & $\begin{array}{l}\text { Temporária } \\
\text { [Interrupção] }\end{array}$ \\
\hline \multicolumn{4}{|c|}{ ORIGEM: PROCESSOS } \\
\hline Falha & Descrição & Impacto & Tipo de Falha \\
\hline Ausência & Falta de colaboração com os parceiros da cadeia & Fluxo Físico & $\begin{array}{l}\text { Temporária } \\
\text { [Interrupção] }\end{array}$ \\
\hline Variabilidade & $\begin{array}{l}\text { Antecipação de pedidos, sem aviso - } \\
\text { Necessidade de aprimorar previsão de vendas - } \\
\text { Demora no tempo de ciclo do pedido - Melhorar a } \\
\text { fiabilidade dos processos }\end{array}$ & $\begin{array}{l}\text { Fluxo Físico } \\
\text { e Fluxo de } \\
\text { Inform. }\end{array}$ & $\begin{array}{l}\text { Temporária } \\
\text { [Interrupção] }\end{array}$ \\
\hline Redução & $\begin{array}{l}\text { Pouca flexibilidade nas atividades operacionais - } \\
\text { Erros no compartilhamento de informações - } \\
\text { Reduzir redundâncias }\end{array}$ & $\begin{array}{l}\text { Fluxo Físico } \\
\text { e Fluxo de } \\
\text { Inform. }\end{array}$ & $\begin{array}{l}\text { Temporária } \\
\text { [Interrupção] }\end{array}$ \\
\hline \multicolumn{4}{|c|}{ ORIGEM: INFORMAÇÃO } \\
\hline Falha & Descrição & Impacto & Tipo de Falha \\
\hline Ausência & $\begin{array}{l}\text { Falta de tecnologia e conectividade - Falta de } \\
\text { informações atualizadas } \quad-\quad \text { Falta }\end{array}$ & Fluxo Físico & $\begin{array}{l}\text { Definitiva } \\
\text { [Ruptura] }\end{array}$ \\
\hline
\end{tabular}




\begin{tabular}{|c|c|c|c|}
\hline & | compartilhamento de informações & & \\
\hline Variabilidade & $\begin{array}{l}\text { Erros nas previsões por mal-uso de TI - Dados } \\
\text { coletados imprecisos - Condições de } \\
\text { infraestrutura interna de TI - Erro ao processar } \\
\text { informações - Distorção da informação } \\
\end{array}$ & $\begin{array}{l}\text { Fluxo Físico } \\
\text { e Inform. }\end{array}$ & $\begin{array}{l}\text { Temporária } \\
\text { [Interrupção] }\end{array}$ \\
\hline Redução & Limitação de informações & $\begin{array}{l}\text { Fluxo Físico } \\
\text { e Inform. }\end{array}$ & $\begin{array}{c}\text { Temporária } \\
\text { [Interrupção] }\end{array}$ \\
\hline \multicolumn{4}{|c|}{ ORIGEM: TRANSPORTE } \\
\hline Falha & Descrição & Impacto & Tipo de Falha \\
\hline Ausência & $\begin{array}{l}\text { Poucas rotas marítimas ao exterior - Reduzido } \\
\text { frete de retorno - Falta de equipamentos }\end{array}$ & Fluxo Físico & $\begin{array}{l}\text { Definitiva } \\
\text { [Ruptura] }\end{array}$ \\
\hline Variabilidade & $\begin{array}{l}\text { Atraso do Navio - Baixa regularidade das } \\
\text { entregas - Interrupção no transporte - Excesso } \\
\text { de hora parada - Poucos aviões cargueiros }\end{array}$ & $\begin{array}{l}\text { Fluxo Físico } \\
\text { e Inform. }\end{array}$ & $\begin{array}{l}\text { Temporária } \\
\text { [Interrupção] }\end{array}$ \\
\hline Aumento & $\begin{array}{l}\text { Custos com sobre-estadias - Aumento de } \\
\text { mercadorias em trânsito - Elevado custo do frete } \\
\text { - Elevado roubo de carga - Taxas elevadas de } \\
\text { sinistros - Excesso de sinistros: roubos, } \\
\text { tombamentos, colisão, capotamento - Ociosidade } \\
\text { de recursos }\end{array}$ & $\begin{array}{l}\text { Fluxo Físico } \\
\text { e Inform. }\end{array}$ & $\begin{array}{l}\text { Definitiva } \\
\text { [Ruptura] e } \\
\text { Temporária } \\
\text { [Interrupção] }\end{array}$ \\
\hline Redução & $\begin{array}{l}\text { Reduzida integração entre modais - Reduzidas } \\
\text { transportadoras de grande tonelagem - Falta de } \\
\text { manutenção da frota - Pouca profissionalização - } \\
\text { Restrição nas grandes cidades - Baixa } \\
\text { manutenção da frota - Reduzido uso de } \\
\text { telemetria Baixos investimentos em ferrovias }\end{array}$ & $\begin{array}{l}\text { Fluxo Físico } \\
\text { e Inform. }\end{array}$ & $\begin{array}{l}\text { Temporária } \\
\text { [Interrupção] }\end{array}$ \\
\hline
\end{tabular}

Fonte: Elaborado pelos autores.

A Figura 5 consolida os dois quadros e gera a proposta de taxonomia para as falhas na cadeia de suprimentos, dando destaque aos quatro macroprocessos e suas interligações no ambiente externo com suas respectivas falhas externas aos macroprocessos. 
Uma proposta de taxonomia para categorização das falhas no ambiente das cadeias de suprimentos Maurício Plaza-Carvajal, Moisés Dutra, Douglas Macedo

Figura 5 - Taxonomia para as falhas na cadeia de suprimentos.

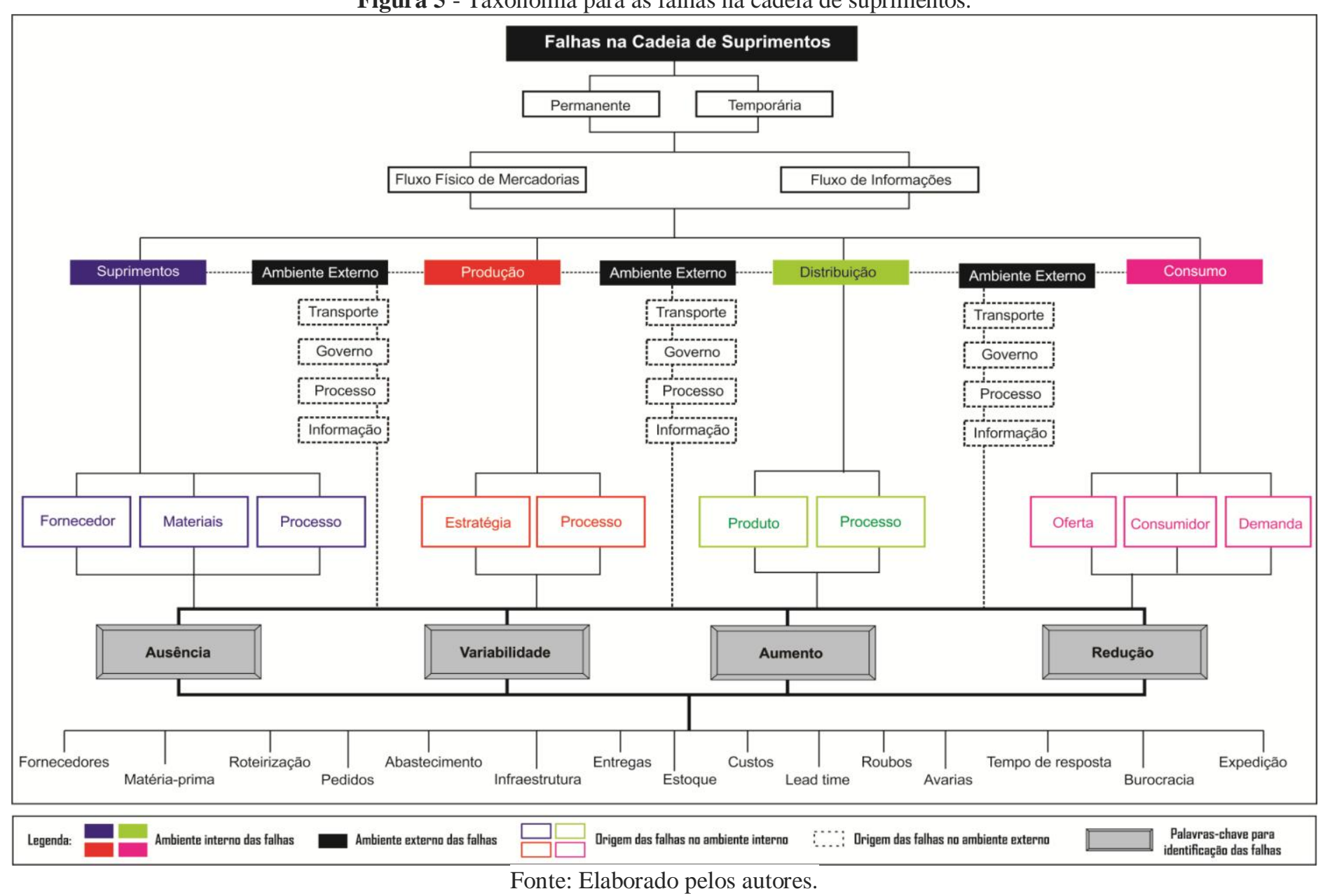




\section{Conclusão}

A pesquisa procurou, a partir de olhar da Ciência da Informação, contribuir com a discussão em torno das falhas que interrompem o fluxo de informações e mercadorias ao longo da cadeia de suprimentos. Foi proposta, a partir da análise de mais de 100 falhas detectadas, uma taxonomia específica para integrar os macroprocessos de suprimentos, produção, distribuição e consumo, com o intuito de ser mais uma ferramenta de auxílio a minimizar, no futuro, essas falhas.

A pesquisa unifica as ocorrências em palavras-chave, na qual foram alocadas todas as falhas encontradas, de modo a facilitar uma posterior solução e integração com os diversos sistemas de gestão atuantes nas cadeias de suprimentos. Os macroprocessos foram analisados individualmente, e foi possível estabelecer algumas similaridades quanto aos vocábulos que definem os locais e a origem das ocorrências de falhas. A literatura evidenciou algumas lacunas quanto ao aprofundamento dos motivos que ocasionam estas falhas, ficando igualmente evidente que, em países com elevado grau de desenvolvimento, a burocracia do governo ou problemas de infraestrutura não costumam ser empecilhos nos processos logísticos. Vale ser ressaltada, nesse momento, a limitação da pesquisa quanto aos vocábulos que fazem parte deste campo de estudo e que não foram abordados na pesquisa, a não ser aqueles que geravam rupturas ou interrupções temporárias nos fluxos da cadeia.

Quanto à proposta de taxonomia, ela apresenta, de forma sucinta e organizada, as falhas nos processos internos e externos à cadeia, permitindo visualizar o risco de rupturas e interrupções resultantes de variáveis internas e externas, especialmente, no que tange a operações de transportes, deficiências de informação, processos interorganizacionais desiguais e entraves do governo. Assim, fica evidente que controlar estas variáveis, em especial, as externas, é extremamente difícil, se não impossível, e, também, deduzir que as falhas sempre farão parte do cenário logístico.

A contribuição desse trabalho encontra-se na ampliação da compreensão das falhas que acometem diversas organizações e que reduzem a 
competitividade do país. Igualmente, a pesquisa espera ter contribuído com a geração de conhecimento para discussões futuras e a ampliação da taxonomia que envolve as cadeias de suprimentos, que, juntamente com a Ciência da Informação, poderão somar conhecimentos no que tange à qualidade e indicadores de desempenho da informação circulante entre os componentes da cadeia de suprimentos. Finalmente, é necessário destacar o papel que trabalhos como este podem desempenhar, no sentido de expandir e, efetivamente, propor um novo olhar, a partir da CI, para áreas de conhecimento correlata, que ainda carecem dessa abordagem informacional.

\section{Referências}

AGUIAR, E. C. et al. Identificação dos riscos em cadeias de suprimentos: um estudo introdutório com empresas da região Sul do Brasil. Revista de Negócios, Blumenau, v. 19, n. 4, p. 64-83, 2015.

ALBANI, H. et al. Determinação de métricas e mapeamento de riscos para a análise de cadeias de suprimentos enxutas. Journal of Lean Systems, Florianópolis, v. 1, n. 1, p. 31-50, 2016.

ARAVECHIA, C. H. M.; PIRES, S. R. I. Gestão de cadeia de suprimentos e avaliação de desempenho. In: ENCONTRO NACIONAL DE PROGRAMAS DE PÓS-GRADUAÇÃO EM ADMINISTRAÇÃO, 23., 2000, Florianópolis. Anais... Florianópolis: UFSC, 2000.

BLACKBURN, B. Taxonomy design types. AIIM E-doc Magazine, Maryland, v. 20, n. 3, p. 14-16, 2006.

BOWERSOX, D.; CLOSS, D. Logística empresarial: o processo de integração da cadeia de suprimentos. São Paulo: Atlas, 2001.

BRANSKI, R. M. O papel da tecnologia da informação no processo

logístico: estudo de casos com operadores logísticos. 2008. Tese (Doutorado em Engenharia de Produção) - Escola Politécnica, Universidade de São Paulo, São Paulo, 2008.

BRÜNING, M. et al. Collaborative recovery from supply chain disruptions: characteristics and enablers. Research, Logistics \& Production, [S.1.], v. 5, n. 3, p. 225-237, 2015.

CAMPOS, M. L. A.; GOMES, H. Taxonomia e classificação: a categorização como princípio. In: ENCONTRO NACIONAL DE PESQUISA EM CIÊNCIA 
DA INFORMAÇÃO, 8., 2007, Salvador. Anais... [S.1.: s.n.], 2007. Disponível em: <http://www.enancib.ppgci.ufba.br/artigos/GT2--101.pdf>. Acesso em: 24 abr. 2017.

CAPAR, I.; ULENGIN, F.; REISMAN, A. A taxonomy for supply chain management literature. 2004. Disponível em:

<https://a1papers.ssrn.com/sol3/papers.cfm?abstract_id=531902>. Acesso em: 4 out. 2016.

CARVALHO, R. A.; GATTS, C. E. N.; AZEVEDO JÚNIOR, D. P. Classificação de fornecedores por Fuzzy Logic. 1998. Disponível em: <http://www.abepro.org.br/biblioteca/ENEGEP1998_ART339.pdf>. Acesso em: 20 abr. 2017.

CHANDRA, C.; TUMANYAN, A. Supply chain system taxonomy: development and application. In: ANNUAL INDUSTRIAL ENGINEERING RESEARCH CONFERENCE, 12., 2003, Portland. Proceedings... Norcross: Institute of Industrial Engineers, 2003.

CHANDRA, C.; TUMANYAN, A. Information modeling to manage supply chain: problems taxonomy. In: ANNUAL INDUSTRIAL ENGINEERING RESEARCH CONFERENCE, 2004, Houston. Proceedings... Norcross: Institute of Industrial Engineers, 2004.

CHOPRA, S.; MEINDL, P. Gerenciamento da cadeia de suprimentos: estratégia, planejamento e operação. São Paulo: Prentice Hall. 2003.

CHRISTOPHER, M. Logística e gerenciamento da cadeia de suprimentos: criando redes que agregam valor. 2. ed. São Paulo: Cengage Learning, 2009.

COELHO, L. C; FOLLMANN, N.; RODRIGUEZ, C. M. T. O impacto do compartilhamento de informações na redução do efeito chicote na cadeia de abastecimento. Gestão \& Produção, São Carlos, v. 16, n. 4, p. 71-583, 2009.

DUTRA, M. et al. Uma abordagem baseada em ontologias para a área de logística. In: ALMEIDA, F. A. S. et al. (Org.). Coletânea luso-brasileira IV: gestão da informação, inovação e logística. Goiânia: Senai, 2013. p. 533-560. Disponível em:

<http://www.cdn.ueg.br/source/observatorio_inhumas/conteudoN/3320/CAP_21 _UMA_ABORDAGEM_BASEADA_EM_ONTOLOGIA.pdf.pdf $>$. Acesso em: 20 abr. 2017.

FIGUEIREDO, S. O impacto da taxonomia nas empresas. Disponível em: <https://webinsider.com.br/2006/11/28/a-importancia-e-o-impacto-dataxonomia-nas-empresas/>. Acesso em: 5 ago. 2016. 
HENDRICKS, K; SINGHAL, V. Supply chain disruptions and corporate performance. In: GURNANI, H. et al. (Org.). Supply chain disruptions. London: Springer London, 2012. p. 1-19.

HILSDORF, W. de C. et al. Modelo para melhoria da integração da cadeia de suprimentos por meio da abordagem da gestão da qualidade. In: ENCONTRO NACIONAL DE ENGENHARIA DE PRODUÇÃO, 25., 2005. Porto Alegre. Anais... Porto Alegre: UFRGS, 2005.

HUDNURKAR, M. et al. Mufti-criteria decision framework for supplier classification in collaborative supply chains: buyer's perspective. International Journal of Productivity and Performance Management, [S.1.], v. 65, n. 5, 2016.

LÓPEZ YEPES, J. Las bases de datos históricas. Anales de Documentación, [S.1.], v. 1, 1998. Disponível em:

<http://revistas.um.es/analesdoc/article/view/3071/3041>. Acesso em: 20 abr. 2017.

MARTÍNEZ, A. et al. Las categorías o facetas fundamentales: una metodología para el diseño de taxonomías corporativas de sitios web argentinos. Ciência da Informação, Brasília, v. 33, n. 2, p. 106-111, 2004.

MEDEIROS, J. W. Taxonomia navegacional facetada: análise à luz dos princípios teóricos da classificação facetada. 2013. Dissertação (Mestrado em Ciência da Informação) - Programa de Pós-Graduação em Ciência da Informação, Universidade Federal de Santa Catarina, Florianópolis, 2013.

MOREIRO GONZÁLEZ, J. A. La industria de los contenidos en la sociedad de la información: ventajas e inconvenientes para la actuación documental. 2002. Disponível em <http://buleria.unileon.es/xmlui/bitstream/handle/10612/1775/Moreiro.pdf?sequ ence $=1>$. Acesso em: 24 abr. 2017.

MORIGI, V. J.; SEMENSATTO, S.; BINOTTO, S. F. T. Ciclo e fluxo informacional nas festas comunitárias. Informação \& Sociedade, João Pessoa, v. 16, n. 1, 2006.

REVISTA VALOR ADUANEIRO. Salvador: Mercatto di Ideias, 2013-2014. Trimestral.

ROJAS MESA, Y. De la gestión de información a la gestión del conocimiento. ACIMED, Ciudad de La Habana, v. 14, n. 1, 2006. Disponível em: <http://bvs.sld.cu/revistas/aci/vol14_1_06/aci02106.htm>. Acesso em: 20 abr. 2017. 
SCHEIDEGGER, A. P. G. et al. Diagnóstico do gerenciamento da cadeia de suprimentos em um restaurante universitário através de estudo exploratório. Revista Produção Online, Florianópolis, v. 15, n. 1, p. 375-402, 2015.

SCHMIDT, W.; RAMAN, A. When supply-chain disruptions matter. Boston: Harvard Business School, 2012. Disponível em:

<http://hbswk.hbs.edu/item/when-supply-chain-disruptions-matter>. Acesso em: 20 abr. 2017.

SELLITTO, M. et al. Análise de risco e classificação de fornecedores em uma cadeia de suprimentos. Engevista, Niterói, v. 15, n. 2, p. 202-213, 2012.

SNYDER, L. V. et al. OR/MS models for supply chain disruptions: a review. IIE Transactions, Norcross, v. 48, n. 2, p. 89-109, 2016.

SOARES, R. A. Gerenciamento da cadeia de suprimentos no setor automobilístico: análise e proposição de melhorias entre uma autopeças e fornecedores. 2007. Dissertação (Mestrado em Engenharia de Produção) Programa de Pós-Graduação em Engenharia de Produção, Universidade Federal de Itajubá, Itajubá, 2007.

SODHI, M. S. et al. Researchers' perspectives on supply chain risk management. Production and Operations Management, Baltimore, v. 21, n. 1, p. 1-13, 2012.

TEIXEIRA, I. T. et al. A cadeia de suprimentos do setor de serviço: o caso de uma empresa de saúde. Gestão e Saúde, Brasília, v. 7, n. 1, p. 3-24, 2016.

TERRA, J. et al. Taxonomia: elemento fundamental para a gestão do conhecimento. [S.1.]: Terra Fórum Consultores, 1998. Disponível em: <http://pessoal.utfpr.edu.br/mansano/arquivos/taxonomia.pdf>. Acesso em: 20 abr. 2017.

VAKHARIA, A. J. et al. Managing supply chain disruptions. Foundations and Trends, Technology, Information and Operations Management, Los Angeles, v. 2, n. 4, p. 243-325, 2009.

VALOR SETORIAL LOGÍSTICA. São Paulo: Valor Econômico, 2012. Anual.

VITAL, L. P. Recomendações para construção de taxonomia em portais corporativos. 2007. Dissertação (Mestrado em Ciência da Informação) Programa de Pós-Graduação em Ciência da Informação, Universidade Federal de Santa Catarina, 2007. Disponível em: $<$ https://repositorio.ufsc.br/bitstream/handle/123456789/89791/241712.pdf?sequ ence $=1$ \&is Allowed=y>. Acesso em: 20 abr. 2017. 
VITAL, L. P. Taxonomia como elemento estruturante em portais corporativos. RDBCI: Revista Digital de Biblioteconomia e Ciência da Informação, Campinas, v. 9, n. 2, p. 25-40, 2012.

VITAL, L. P.; CAFÉ, L. Proposta para o desenvolvimento de taxonomias em portais corporativos. Perspectivas em Ciência da Informação, Belo Horizonte, v. 16 , n. 4 , p. 42-54, 2011.

VITAL, L. P.; FLORIANI, V. M.; VARVAKIS, G. Gerenciamento do fluxo de informação como suporte ao processo de tomada de decisão: revisão.

Informação \& Informação, Londrina, v. 15, n. 1, p. 85-103, 2010.

VOGEL, M. Taxonomia: produto ou processo? 2010. Disponível em:

<https://www.academia.edu/13763861/Taxonomia_produto_ou_processo>. Acesso em: 20 abr. 2017.

WOODS, E. The corporate taxonomy: creating a new order. KMWorld, Camden, v. 13, n. 7, 2004. Disponível em:

<http://www.kmworld.com/Articles/Editorial/Features/The-corporatetaxonomy-creating-a-new-order-9566.aspx>. Acesso em: 20 abr. 2017.

YAMAOKA, E. J.; CARVALHO, I. M.; GAUTHIER, F. O. Taxonomia corporativa e aprendizagem organizacional: caminho para a ambidestria. In: SIMPOSIO SOBRE LA SOCIEDAD DE LA INFORMACIÓN, 10., 2012, La Plata. Anais... La Plata: Facultad de Informática, 2012.

\title{
A proposal of taxonomy for categorizing failures in supply chain
}

\section{environments}

\begin{abstract}
The informational question permeates the most diverse areas of knowledge. Regarding the industrial environment, high costs are attributed to the industry due to deficiencies in the informational and in the merchandise cycles. Failures cause disruption by reducing the competitiveness of organizations. This paper aims to categorize these supply chain failures. The main objective is, based on an Information Science (CI) perspective, to propose a taxonomy for existing flaws, based on the following objectives: (i) identify the main faults in the supply chains evidenced in the literature; (ii) position each fault within the logistical and informational flow, and (iii) group, organize and hierarchize these failures. This is a bibliographical, exploratory and qualitative research. The results allow us to affirm that there are several similarities that define the locations and origin of failure occurrences, as well as the perception that, based on the proposed taxonomy, there are high risks of interruptions and ruptures in the supply chain. Finally, with this paper, we hope to contribute to a
\end{abstract}


broader understanding of the failures of various organizations and to the generation of knowledge for future discussions involving supply chains and Information Science. There is a vast space of collaboration on the informational issue in the supply chain, which is not yet adequately filled by CI. In this sense, this work also intends to contribute to reduce this gap a little.

Keywords: Supply chain. Information flows. Failures. Taxonomy.

Recebido em: 17/02/2017

Aceito em: 27/04/2017 